\title{
Thyroid Hormones, Oxidative Stress, and Inflammation
}

\author{
Antonio Mancini, ${ }^{1}$ Chantal Di Segni, ${ }^{1}$ Sebastiano Raimondo, ${ }^{1}$ Giulio Olivieri, ${ }^{1}$ \\ Andrea Silvestrini, ${ }^{2}$ Elisabetta Meucci, ${ }^{2}$ and Diego Currò ${ }^{3}$ \\ ${ }^{1}$ Operative Unit of Endocrinology, Catholic University of the Sacred Heart, 00168 Rome, Italy \\ ${ }^{2}$ Institute of Biochemistry and Clinical Biochemistry, Catholic University of the Sacred Heart, 00168 Rome, Italy \\ ${ }^{3}$ Institute of Pharmacology, Catholic University of the Sacred Heart, 00168 Rome, Italy
}

Correspondence should be addressed to Antonio Mancini; mancini.giac@mclink.it and Andrea Silvestrini; andrea.silvestrini@unicatt.it

Received 31 December 2015; Revised 14 February 2016; Accepted 15 February 2016

Academic Editor: Joilson O. Martins

Copyright (C) 2016 Antonio Mancini et al. This is an open access article distributed under the Creative Commons Attribution License, which permits unrestricted use, distribution, and reproduction in any medium, provided the original work is properly cited.

Inflammation and oxidative stress (OS) are closely related processes, as well exemplified in obesity and cardiovascular diseases. OS is also related to hormonal derangement in a reciprocal way. Among the various hormonal influences that operate on the antioxidant balance, thyroid hormones play particularly important roles, since both hyperthyroidism and hypothyroidism have been shown to be associated with OS in animals and humans. In this context, the nonthyroidal illness syndrome (NTIS) that typically manifests as reduced conversion of thyroxine $\left(\mathrm{T}_{4}\right)$ to triiodothyronine $\left(\mathrm{T}_{3}\right)$ in different acute and chronic systemic conditions is still a debated topic. The pathophysiological mechanisms of this syndrome are reviewed, together with the roles of deiodinases, the enzymes responsible for the conversion of $\mathrm{T}_{4}$ to $\mathrm{T}_{3}$, in both physiological and pathological situations. The presence of OS indexes in NTIS supports the hypothesis that it represents a condition of hypothyroidism at the tissue level and not only an adaptive mechanism to diseases.

\section{Introduction}

Oxidative stress (OS) is defined as an unbalance between the production of prooxidant substances and antioxidant defenses. The most important prooxidants are the reactive oxygen species (ROS) and reactive nitrogen species (RNS) [1]. The ROS family includes superoxide anion, hydroxyl radical, hydrogen peroxide, and hypochlorous acid. The first three substances are produced in vivo mainly by the mitochondrial respiratory chain during the oxidative metabolism of energetic substrates $[2,3]$. They are regulators of redox-sensitive pathways involved in cellular homeostasis [4] and influence some transcription factors, in addition to the endogenous antioxidant pool [4-7]. RNS are peroxynitrite, produced by the reaction of nitric oxide (NO) with superoxide, and nitrosoperoxycarbonate, formed by the reaction of peroxynitrite with carbon dioxide. ROS and RNS are considered important pathogenetic factors in different diseases [8]. Among them, a particular pathogenetic role is played by the free radicals, that is, superoxide anion and hydroxyl radical, that are molecules characterized by high chemical reactivity due to a single unpaired electron in the external orbital.

In some cell types, such as leukocytes, endothelial and mesangial cells, fibroblasts, thyrocytes, oocytes, Leydig cells, and adipocytes, ROS generation could play functional roles [9]. Dual oxidases (DUOX), enzymes crucial for hydrogen peroxide generation, are essential for thyroid peroxidase(TPO-) catalyzed hormone synthesis [10]. Two oxidases of such family are present in thyroid (DUOX1 and DUOX2). They work in conjunction with DUOXA1 and DUOXA2, which are maturation factors that allow DUOX enzymes to translocate to the follicular cell membrane and exert their enzymatic activity [10]. In addition, NADPH oxidase 4 (NOX4) [11] is a new intracellular ROS generating system recently described in the human thyroid gland.

An increased ROS production by the respiratory chain resulting from the rise of the energetic demand or substrate availability [12], as occurs in obesity, or mitochondrial dysfunction or impairment, can produce cell damage and contribute to the pathophysiology of different diseases, such as 
inflammatory (e.g., rheumatoid arthritis) and cardiovascular (e.g., myocardial infarction) diseases [2]. A pathophysiological role of ROS has been also suggested in diabetes mellitus, in which oxidation accompanies glycation in vivo and the antioxidant capacity is decreased, resulting in increased susceptibility to oxidative stress [13].

Different defensive mechanisms that protect against the free radical damage have been characterized in various cellular localizations, including the endoplasmic reticulum, mitochondria, plasma membrane, peroxisomes, and cytosol [2]. Enzymes such as superoxide dismutase (SOD), catalase (CAT) and glutathione peroxidase (GPx), and transitionmetal binding proteins, such as transferrin, ferritin, and ceruloplasmin, prevent the production of or rapidly inactivate free radicals. SOD accelerates the dismutation process of superoxide anion in hydrogen peroxide and molecular oxygen that normally occurs with a rate constant $10^{4}$-fold lower. CAT detoxifies hydrogen peroxide by transforming it in water and molecular oxygen. GPx also participates in hydrogen peroxide detoxification when hydrogen peroxide levels are high. In addition, GPx detoxifies lipid peroxides by transforming them in the corresponding alcohols. "Scavengers" molecules, including both water-soluble, such as albumin, bilirubin, ascorbic acid, urates and thiols, and liposoluble, such as Vitamin $\mathrm{E}$ and coenzyme $\mathrm{Q}_{10}\left(\mathrm{CoQ}_{10}\right)$, substances interrupt the lipid-peroxidation chain by reacting with and neutralizing the intermediate radicals. The high diffusion rate of scavengers, particularly the liposoluble ones in biological membranes, allows them to intercept radicals and transform them into more stable molecules, thus stopping the radical chain. Sometimes scavengers can be regenerated. A third defensive mechanism uses processes which remove the molecules damaged by the oxidative attack, allowing the reconstitution of normal structures (e.g., specific phospholipases remove the peroxidized fatty acids, making the enzymatic reacylation of damaged molecules possible) [2].

The production of ROS and RNS can occur at the cellular level in response to metabolic overload caused by the overabundance of macronutrients. In addition, mitochondrial dysfunction and endothelial reticulum stress contribute to adipose tissue metabolic derangement in obese patients [14, 15]. ROS generation is further maintained by an inflammatory response, feeding a vicious circle. This picture is worse in pre- and postpubertal children, because puberty alters some inflammatory markers associated with endothelial dysfunction (adipocytokine levels, OS, and insulin sensitivity).

Recent findings suggest that mitochondrial reactive species are signalling molecules that mediate the production of proinflammatory cytokines, thus connecting OS and inflammation. This topic has been extensively studied in cardiovascular diseases [16].

However, besides inflammation, OS can be related to hormonal derangement in a reciprocal way. Some hormones influence antioxidant levels; on the other hand, OS can modify synthesis, activity, and metabolism of hormones. Therefore, OS is related to both systemic inflammation and hormonal derangement. In particular, thyroid hormones play important roles in antioxidant modulation, as demonstrated in different in vitro and in vivo studies. Reduced glutathione (GSH) is an important cofactor of both antioxidant enzymes and deiodinases, the enzymes responsible for the conversion of thyroxine $\left(\mathrm{T}_{4}\right)$ to triiodothyronine $\left(\mathrm{T}_{3}\right)$. Moreover, plasma levels of small antioxidant molecules, such as Vitamin $\mathrm{E}$ and $\mathrm{CoQ}_{10}$, and thyroid hormones are closely related to each other $[2,17]$. Both hyperthyroidism and hypothyroidism have been shown to be associated with OS and special cases are the autoimmune thyroiditis or the functional picture of low- $\mathrm{T}_{3}$ syndrome, observed in acute and chronic nonthyroidal illness syndrome (NTIS) [17-19]. It is still debated whether NTIS represents an adaptive response or a real hypothyroidism at the tissue level. Therefore, studies on OS in NTIS are important to gain knowledge about the pathophysiology of the syndrome itself.

In this review, we firstly examine the relationships between OS and inflammation. Then, we present available data on thyroid hormones and antioxidant regulation. Finally, we report the results of investigations on the relationships between inflammatory mediators and OS in NTIS, in the attempt of hypothesizing a reciprocal influence between tissue hypothyroidism (as primary cause or secondary to inflammation) and OS. Thus, the aim of our review is to discuss and clarify the relationships between thyroid hormones and parameters of OS in the context of the inflammatory diseases.

\section{Oxidative Stress and Inflammation}

Different mediators produced by the adipose tissue may potentially cause an increase of systemic and local ROS and RNS. Thus, the dysregulation of signalling pathway originating in adipocytes, as observed in obese patients, can induce and perpetuate inflammation and OS. Recent studies clearly indicate that the adipose tissue can be considered as an endocrine organ producing different proteins (adipokines) with wide biologic activities. In addition, after maturation from the stage of preadipocytes, the adipocytes gain functions similar to those of macrophages, including the ability to be activated by components of the bacterial wall and to synthesize and secrete cytokines [20]. Moreover, during the periods in which weight gain or loss occurs, the cellular composition of the adipose tissue dynamically changes, showing variations in the levels of various cell types represented in the tissue, in particular vascular and immune cells. The levels of the latter, in particular the macrophages, importantly increase in obese patients. The macrophages seem to play important roles in the pathogenesis of insulin resistance associated with obesity, through the production of Monocyte Chemoattractant Protein-1 (MCP-1) and the modulation of the spreading and the growth of the adipose tissue itself [21]. Monocytes mobilized and attracted by MCP1 , together with neutrophils and lymphocytes $\mathrm{T}$ present in the adipose tissue, originate an inflammatory response that is reinforced by the stimulation of the synthesis and secretion of tumor necrosis factor (TNF) by macrophages, in turn induced by the increased production of free fatty acids (FFAs) by adipocytes. In addition, a two-way interaction between 
adipocytes and macrophages seems to develop, by which the macrophages stimulate the expression and release of MCP-1 from the adipocytes through ROS production. By this way a vicious circle is established, which may promote a chronic inflammatory status gradually more and more intense, typical of obesity and its complications. Finally, the macrophages regulate the remodelling of the adipose tissue when a chronic positive energetic balance ensues. Different pathways are activated in adipocytes depending on whether subtype M1 or M2 macrophages are stimulated, that regulate adipocyte proliferation, growth, and survival. The induced changes are responsible for the appearance of a hypertrophic or hyperplastic obesity. In case of the prevalence the M1 proinflammatory macrophagic subtype, the reduced survival and proliferation of the preadipocytes will cause an inadequate adipocyte reserve; consequently, the energetic backlog, through an excessive hypertrophy, will produce a dysfunctional adipose tissue, which will perpetuate the inflammatory process and, in the long term, produce insulin resistance. Conversely, if the M2 macrophagic subtype is prevalent, the functional pool of preadipocytes will be favoured. They will differentiate into adipocytes, contributing to the formation of an adequate hyperplastic adipose tissue with preserved cell functions and insulin sensitivity [22].

Therefore, obesity is associated with increased secretion of proinflammatory hormones and cytokines (leptin, resistin, TNF- $\alpha$, and interleukin- (IL-) 6) and decreased release of adipokines that downregulate inflammation (adiponectin, IL-10). Recent studies [23] show that not only the amount but also the kind of adipose tissue, as well as the kinds of fats in the diet, influence in different ways this chronic inflammatory state.

Many other mechanisms reviewed by Siti et al. [16] reinforce the link between OS and inflammation. Among these, there is the overexpression of endothelin that induces ROS production in endothelial cells by increasing NADPH oxidase activity [24]; on the other hand, OS causes an increase in angiotensin converting enzyme [25], creating a loop with the previously cited mechanism. Another important mechanism is the OS-induced $\mathrm{Ca}^{2+}$ influx, responsible for inflammatory processes [26].

In diabetes, the chronic inflammation, the increase in FFA levels, and the overactivation of the renin-angiotensin system contribute to insulin resistance via OS [27]. TNF- $\alpha$, an important mediator of inflammation, interferes with insulin signals through the activation of the PI3-kinase pathway in endothelial cells [28]. A systemic lipid infusion, that induces acute elevation of plasma FFA levels, causes the activation of the NF-kB pathway, OS, and impairment of endotheliumdependent vasodilatation. In addition, insulin effects on vasodilatation, NO production, and muscle capillary recruitment are blunted by the lipid infusion [29-32]. Regarding this subject, we have shown that a naturally enriched antioxidant diet is capable of improving insulin sensitivity and metformin effects in adult obese patients [33].

Other studies confirmed the link between OS, vascular inflammation, and hypertension-associated vascular changes [34]. Moreover, it is well known that oxidized LDL have a key role in the initiation and progression of the atheromatous plaque $[16,35]$; a main role has been recently attributed to the lectin-like oxidized LDL receptor-1 (LOX-1), which is upregulated by the exposure to inflammatory stimuli [36]. The role of the renin-angiotensin system in OS-related injury of endothelial cells has been recently reviewed [37]. Elegant studies conducted in experimental animal models, such as the ApoE knock-out mouse, confirmed an oxidant/antioxidant unbalance in the atherosclerotic process [38-40]. A large number of studies have been published on this topic, which, however, is not among the subjects of the present review. Nevertheless, they overall confirm the association between inflammation and OS.

\section{The Role of Thyroid Hormones in Antioxidant Regulation}

The role of thyroid in the regulation of the antioxidant systems has been recently reviewed in the context of the reproductive endocrinology [41]. It is well known that thyroid function influences the ovarian activity. ROS play physiological roles in the ovary and hypothyroidism, or a low$\mathrm{T}_{3}$ syndrome, can induce ovarian dysfunction by interfering with the antioxidant systems.

OS has been shown to be associated with both hyperthyroidism and hypothyroidism [42]. However, the mechanisms by which OS is generated in these two clinical conditions are different: increased ROS production in hyperthyroidism and low availability of antioxidants in hypothyroidism.

Some complications of hyperthyroidism in target tissues are caused by OS [43]. Thyroid hormones per se can act as oxidants and produce DNA damage (contrasted by CAT), probably through the phenolic group, which is similar to that of steroidal estrogens [44]. Many other mechanisms, as previously reviewed [45], can be involved, in particular the enhanced Nitric Oxide Synthase (NOS) gene expression with $\mathrm{NO}$ overproduction and the activation of hepatic NF-kB with the consequent increase in cytokines levels which induces ROS production. On the other hand, other mechanisms regulated by thyroid hormones carry out a fine regulation of the oxidative status via autoloop feedback. Among them, we underline the role of Uncoupling Protein- (UCP-) 2 and Uncoupling Protein-3. Data obtained in plants and animals indicate that these molecules have antioxidant activity [4648]. However, only $\mathrm{T}_{3}$ seems to regulate UCP, whereas no effect is exerted by $\mathrm{T}_{4}[49,50]$. An opposite effect is induced by estrogens, which increase ROS production by repressing UCP [51].

The increased turnover of mitochondrial proteins and mitoptosis also participate in the regulation of the oxidative status, by removing the mitochondria damaged by OS [52]. These processes are regulated by peroxisome proliferatoractivated receptor gamma coactivator-1, which in turn is upregulated by $\mathrm{T}_{3}$ administration [53].

Thyroid hormones influence lipid composition of rat tissues and consequently the susceptibility to OS. However, the response is tissue-specific, and discrepant effects of $\mathrm{T}_{3}$ and $\mathrm{T}_{4}$ have been reported. In rat liver, $\mathrm{T}_{3}$-induced hyperthyroidism 
was found to be associated with altered lipid-peroxidation indexes, including elevated levels of thiobarbituric reactive substances (TBARS) and lipid hydroperoxides that are byproducts of lipid peroxidation [45, 53-55]. On the contrary, no changes in TBARS production were found in homogenized livers from rats made hyperthyroid by administration of $\mathrm{T}_{4}$ over a 4-week period [56]. No significant changes of TBARS or lipid hydroperoxides were observed in testes of hyperthyroid adult rats as well; however, hyperthyroidism promoted protein oxidation in testes, as indicated by the enhanced content of protein-bound carbonyls [57]. In addition, it should be emphasized that the effects of hyperthyroidism on the activity of antioxidant enzymes, including $\mathrm{Mn}$ - or $\mathrm{Cu}, \mathrm{Zn}-\mathrm{SOD}, \mathrm{CAT}$, and GPx, depend on the tissue investigated, with $\mathrm{T}_{3}$ and $\mathrm{T}_{4}$ having differentiated effects [58].

At the systemic level, hyperthyroidism has been associated with reduced circulating levels of alpha-tocopherol $[59,60]$ and $C_{0} Q_{10}[60,61]$ in humans. $C_{0} Q_{10}$ showed a trend toward higher levels in hypothyroidism [61]. Thus, it seems to be a sensitive index of tissue effect induced by thyroid hormones in situations in which drug interference, such as treatment with amiodarone [62], or systemic illness inducing low- $\mathrm{T}_{3}$ conditions [63] complicate the interpretation of thyroid hormone levels.

On the other side, data on hypothyroidism and OS in humans are conflicting. In a group of patients with primary hypothyroidism, Baskol et al. [64] found high plasma levels of malondialdehyde (MDA), an OS marker that is formed by lipid peroxidation, and NO, low activity of paraoxonase(PON-) 1, an enzyme synthetized in the liver with antioxidant properties, and SOD levels not significantly different from those of controls. Interestingly, the treatment with thyroid hormones decreased MDA levels and increased PON-1 activity, even though values similar to those observed in controls were not reached [64]. They hypothesized that in patients with hypothyroidism the prooxidant environment could play a role in the development of atherosclerosis. Elevated MDA levels were also shown in subclinical hypothyroidism [65]. In this setting, the increased OS was attributed primarily not only to the decrease in antioxidants levels, but also to altered lipid metabolism, since a significant correlation among MDA and LDL-cholesterol, total cholesterol, and triglyceride levels was found. Total antioxidant status (TAS) was similar in overt hypothyroidism, subclinical hypothyroidism, and controls.

Excess TSH is known to directly produce OS [66]. Other studies confirmed the lipid peroxidation both in overt hypothyroidism and in subclinical hypothyroidism [67] as indicated by MDA elevation; protein oxidation has been reported as well, with elevation of protein carbonyls [67]. In this study, the correlation analysis suggested that both the TSH increase and the MDA elevation contribute to protein damage. Finally, different studies reported NO elevation [68, 69].

Data on other parameters are more conflicting. As far as PON-1 is concerned, a decreased activity of this enzyme was observed both in hypothyroidism and in hyperthyroidism [70], whereas no significant differences with respect to controls were shown in other studies [68]. Increased levels of TBARS, but also antioxidants, such as SOD, CAT, and
Vitamin E, have been also reported [71]. All these parameters correlated with $\mathrm{T}_{3}$ and the correlation between $\mathrm{T}_{3}$ and CAT remained significant also when corrected for total cholesterol. TBARS elevation was shown in both overt hypothyroidism and subclinical hypothyroidism $[69,72]$, but these findings were not confirmed in other studies $[68,73]$.

Another matter of discussion is whether OS is related to hypothyroidism per se or to lipid profile alterations caused by thyroid disfunction, as reported above. Indeed, Santi et al. [74] reported OS in subclinical hypothyroidism, as shown by reduced arylesterase and increased TBARS and CAT, but they attributed this pattern to hypercholesterolemia.

We showed low total antioxidant capacity (TAC) levels in hypothyroid patients [75] and increased $\mathrm{CoQ}_{10}$ plasma levels in secondary hypothyroidism. This latter finding is mainly to be put in correlation with the metabolic role of $\mathrm{CoQ}_{10}$ in the mitochondrial respiratory chain and its consequent reduced cell use in hypothyroid patients. In secondary hypothyroidism, the picture is complicated by concomitant alterations of other pituitary-dependent axes, which can have opposite effect on $\mathrm{CoQ}_{10}$ plasma levels. Acromegaly and hypoadrenalism are characterized by low $\mathrm{CoQ}_{10}$ plasma concentrations; however, when they are associated with hypothyroidism, this latter has a predominant effect $[75,76]$.

New perspectives concern DUOX, DUOXA, and NOX4. Cases of hypothyroidism due to mutation of DUOX or DUOXA genes have been reported in the literature [10, 11]. In addition, alterations of NOX 4 could be associated with thyroid cancer (via activation by H-Ras oncogene) and Hashimoto's thyroiditis, in which the increased extracellular expression of this enzyme raises Intercellular Adhesion Molecule-1 (ICAM-1) expression and cytokine release [77, 78].

Finally, another study conducted on patients affected by subclinical hypothyroidism secondary to Hashimoto's thyroiditis did not show any difference in endogenous MDA levels between hypothyroid patients and controls; however, MDA induction by the prooxidant $2,2^{\prime}$-azobis-(2amidinopropane) hydrochloride was markedly augmented in hypothyroid patients. This response in serum was not accompanied by a similar pattern in the LDL fraction: in fact, copper-induced MDA production did not differ in patients affected by subclinical hypothyroidism with respect to controls, whereas it was significantly different from controls in patients with overt hypothyroidism [79]. Studies on patients with thyroiditis should be, however, interpreted with caution, in that both tissue inflammation and systemic inflammation are present in this autoimmune disorder.

The experimental procedures by which hypothyroidism is induced affect the OS findings. Hypothyroidism obtained by surgical thyroid resection in rats was associated with decreased OS in heart [80] and kidney [81]. On the contrary, drug-induced hypothyroidism was associated with increased lipid peroxidation in amygdala [82] and hippocampus in rats $[82,83]$. Other cerebral areas, including the cerebellum, remained unaffected [84]. The latter findings, however, were not confirmed in other studies $[82,83]$. Similarly, cell damage in various organs, including heart, spleen, liver, lung, and 
kidney, has been found in animals following methimazole treatment, but not after thyroidectomy [84]. Some studies, however, indicate that the organ damage is not consequent to the hypothyroidism per se, but to the drug itself $[85,86]$.

In the latest years, the attention has been concentrated on the damage induced by $O S$ in certain organs, including liver, bone, skeletal muscle, and particularly the heart [53]. The metabolism of cardiomyocytes depends on serum $\mathrm{T}_{3}$, in that these cells lack a significant deiodinase activity [87]. Increased, decreased, or unmodified levels of total SOD, Mn-SOD, Cu,Zn-SOD, GPx, GSH, or Vitamin E have been reported in cardiomyocytes in response to hypothyroidism [88]. Unchanged or decreased levels of various other antioxidant molecules or parameters, such $\mathrm{CoQ}_{9}, \mathrm{CoQ}_{10}$, and TAC, have been also reported. These findings indicate that the evaluation of a single OS parameter is not a reliable index of the cellular oxidative status and the evaluation of TAC depends on the measurement method used.

OS has been also involved in the pathophysiology of schizophrenia. In fact, higher plasma levels of MDA and total plasma peroxides have been found in schizophrenic patients with respect to control subjects, which showed a significant correlation with $\mathrm{T}_{3}$ levels [89].

The thyroid itself can be damaged by OS, which occurs in case of iodine excess. This topic has been studied both in vitro and in animals fed with a diet rich in iodide [90, 91]. Iodide has a stimulatory action of on hydrogen peroxide generation in thyroid slices and induces thyroid cell apoptosis at high concentrations [92].

Vitamin E has been shown to be protective against the tissue damage induced by peroxyl radicals, mainly not only by preserving the polyunsaturated fatty acids in biological membranes, but also by reducing the activity of NADPH oxidase [53].

\section{The Model of Low-T ${ }_{3}$ Syndrome}

Low- $\mathrm{T}_{3}$ syndrome is a condition characterized by a reduced peripheral conversion of $\mathrm{T}_{4}$ to $\mathrm{T}_{3}$ in the presence of normal thyroid hormone secretion. It occurs in a variety of nonthyroidal illness (NTI) and is defined as nonthyroidal illness syndrome (NTIS). The most important acute conditions in which the low- $\mathrm{T}_{3}$ syndrome occurs include starvation and eating disorders and critical illness. During starvation (especially carbohydrate deprivation) and nonthyroid illness, deiodination of $\mathrm{T}_{4}$ to $\mathrm{T}_{3}$ is rapidly inhibited, causing the low- $\mathrm{T}_{3}$ syndrome. As the illness progresses to more and more severe stages, a more complex syndrome with low$\mathrm{T}_{3}$ and $\mathrm{T}_{4}$ ensues. In critical illness, many other changes of the pituitary-thyroid axis have been shown, including attenuated response to TRH, low tissue uptake of thyroid hormones, and altered thyroid hormone metabolism. A low$\mathrm{T}_{3}$ syndrome caused by the reduced peripheral conversion from the prohormone $\mathrm{T}_{4}$ is also observed in different chronic diseases, including chronic kidney disease, liver failure, and chronic inflammatory diseases.

A component of NTIS can be related to cachexia, which is common in chronic systemic inflammation, renal failure, and heart failure. This field has been widely investigated in cancer patients. Cachexia represents a hypermetabolic wasting syndrome with progressive depletion of adipose tissue and skeletal muscle mass, often accompanied by anorexia [93]. Among the mediators of cachexia in cancer patients there are several cytokines and hormones also involved in the pathophysiology of NTIS. They are produced by tumour cells or macrophages surrounding them, as expression of the interaction between the neoplasia and the host environment. The most important are TNF- $\alpha$, IL-1, IL-6, interferon- (IFN-) $\gamma$, proteolysis-inducing factor (PIF), angiotensin II, and myostatin, a member of the transforming growth factor- $\beta$ superfamily. Interestingly, the signal transduction pathways of many of these substances involve NF-kB, the activity of which is in turn related to ROS levels. In fact, it has been shown that hydrogen peroxide, PIF, and angiotensin II activate NF$\mathrm{kB}$ in myotubes [94] and the treatment of myotubes exposed to TNF- $\alpha$, PIF, or angiotensin II with antioxidants reduces the NF-kB binding to DNA $[94,95]$. In addition, it has been reported that the treatment of MAC16 colon-tumour bearing mice with Vitamin $\mathrm{E}$ reduces protein degradation in skeletal muscle [95]. Finally, some cytokines, including TNF- $\alpha$, IL1 , IL-6, and IFN- $\gamma$, mimic leptin signalling, inducing central suppression of appetite [96].

The condition of NTIS is considered as an adaptive response rather than true hypothyroidism. Thyroid replacement therapy is not usually required, but this topic is still debated, since indirect signs of true hypothyroidism at tissue level have been shown. Some molecular mechanisms of NTIS are known, but more studies are necessary to further elucidate its pathogenesis. Indeed, it is probable that a full understanding of the pathophysiological mechanisms at the tissue level will allow the identification of patients who would benefit from replacement therapy. Our discussion will focus on the roles of cytokines and OS in the pathophysiology of NTIS.

The roles of cytokines as key molecules involved in coordinating the hormone, immune, and inflammatory responses to a variety of stressful stimuli are well known [18]. In a series of septic patients studied shortly after admission to the ICU, total $\mathrm{T}_{4}\left(\mathrm{tT}_{4}\right)$, free $\mathrm{T}_{4}\left(\mathrm{fT}_{4}\right)$, total $\mathrm{T}_{3}\left(\mathrm{tT}_{3}\right)$, and TSH plasma concentrations were depressed, and plasma levels of IL- $1 \beta$, sIL- 2 receptor, and TNF- $\alpha$ were elevated [97], indicating the establishment of central TSH suppression. The hypothalamic-pituitary-adrenal axis was activated as expected. Continuous infusion of IL-1 in rats causes reduction of TSH, free $\mathrm{T}_{3}\left(\mathrm{fT}_{3}\right)$, and $\mathrm{fT}_{4}$ plasma levels. Higher doses of IL-1 induced a febrile reaction and suppression of food intake, with a cascade of events altering thyroid hormone economy [98]. However, IL-1 did not decrease the hepatic $5^{\prime}$-deiodinase activity that, on the contrary, is typically reduced in NTIS.

TNF is another proinflammatory cytokine that is thought to be involved in many of the alterations associated with NTIS. Infusion of rTNF in man decreases serum $\mathrm{T}_{3}$ and $\mathrm{TSH}$ and increases reverse- $\mathrm{T}_{3}\left(\mathrm{rT}_{3}\right)$ [99]. These findings suggest that TNF could be involved in the IL-6-mediated suppression of the hypothalamic-pituitary axis. However, the involvement of TNF in NTIS pathophysiology was not confirmed in other studies, in which the effects of endotoxin 
on thyroid hormones in humans were not counteracted by TNF- $\alpha$ blockade through specific IgG fusion proteins [100]. TNF- $\alpha$ was found in in vitro studies to activate NF-kB [101], which in turn inhibits $\mathrm{T}_{3}$-induced expression of deiodinase 1 (D1).

An important pathophysiological role in NTIS has been attributed to IL-6, which is often elevated in serum of NTIS patients [102] in an inversely proportional manner with respect to $\mathrm{T}_{3}$ levels [103]. Short term infusion of rIL6 to healthy volunteers [104] suppressed TSH secretion, whereas daily injections over a 6-week period only slightly decreased $\mathrm{T}_{3}$ levels and transiently increased $\mathrm{rT}_{3}$ and $\mathrm{fT}_{4}$ concentrations.

Deiodinases are dimeric selenoproteins that catalyze the stereospecific removal of iodine atoms from the prohormone $\mathrm{T}_{4}$, generating the active and inactive isomers of both $\mathrm{T}_{3}$ and diiodothyronine $\left(\mathrm{T}_{2}\right)$. Different isoforms are expressed with tissue specificity: D1 and D2, via the deiodination of the outer ring, convert $\mathrm{T}_{4}$ to active $\mathrm{T}_{3} ; \mathrm{D} 3$, via the inner ring deiodination, converts $\mathrm{T}_{4}$ to inactive metabolites: $\mathrm{rT}_{3}$ and $3,3^{\prime}-T_{2}[105,106]$. Phylogenetic analysis suggests that $\mathrm{D} 1$ is the oldest vertebrate deiodinase, while $\mathrm{D} 2$ is the most recent one; this is in agreement with the key role of D2 as the most specialized and finely regulated member of this enzyme family [106].

Deiodinases play pivotal roles in the regulation of the intracellular levels of active thyroid hormones [107]. D2 is located in the endoplasmic reticulum and plays the primary role in the conversion of $\mathrm{T}_{4}$ to $\mathrm{T}_{3}$. D1 has lower affinities for the substrates with respect to D2 and seems to be mainly a scavenger enzyme, involved in iodine recycling. Furthermore, the balance between D2 and D3 activities seems to be an important factor in determining the amount of $\mathrm{T}_{3}$ available to bind the nuclear receptors. Different mechanisms regulate the expression of deiodinase genes (DIO1, DIO2, and DIO3), first of all the levels of thyroid hormones: hyperthyroidism suppresses D2 activity and DIO2 expression, whereas hypothyroidism exerts the opposite effects [108]. The ubiquitination of the enzymes, which can be reversible to assure the appropriate protein homeostasis, is a mechanism of finer regulation of deiodinase activity [109].

D2 plays important roles in the regulation of the energetic balance as well. It has been shown that animal exposure to low temperatures activates D2 in brown adipose tissue through catecholamine-induced cAMP production. The resulting increase in $\mathrm{T}_{3}$ levels induces thermogenic genes, including UCP-1 [110]. In addition, DIO2 expression is upregulated by bile acids in the brown adipose tissue of mice through the increase in cAMP levels. When fed with a high fat diet supplemented with bile acids, the animals do not gain weight, showing a resistance to diet-induced obesity, and this effect is absent in D2 knock-out animals [111, 112].

Recent studies on the effects of IL- 6 on both endogenous cofactor-mediated and dithiothreitol-stimulated deiodinase activity in human cell lines [112] have shown that $\mathrm{T}_{3}$ generation by $\mathrm{D} 1$ and $\mathrm{D} 2$ is suppressed by IL-6, despite an increase in expression of deiodinases. The inhibitory action of IL-6 is prevented by the addition of $\mathrm{N}$-acetyl-cysteine (NAC), an antioxidant that restores intracellular GSH concentrations, suggesting the involvement of prooxidant substances in IL6-induced effects.

Finally, the interaction between the complex network of cytokines and the hypothalamic-pituitary-thyroid axis probably plays pathogenetic roles in NTIS, even though it is not possible to build a simplistic model [18]. Also the role of cytokines in eating disorders and related thyroid hormone alterations has been recently reviewed [113].

Different conditions in which NTIS develops are associated with OS, due to augmented production ROS or RNS [114]. Since thyroid hormones, as above discussed, increase ROS generation, low- $\mathrm{T}_{3}$ could be viewed as a compensatory mechanism. In fact, low- $\mathrm{T}_{3}$ concentrations would be associated with decreased metabolic rate that would reduce further radical generation. Cytosolic thiols, particularly GSH, and Thioredoxin (Trx), which are also deiodinase cofactors, contribute to the maintaining of a reducing intracellular environment. Thus, their depletion, consequent to their buffering effect on radical propagation, could interfere with the conversion of $\mathrm{T}_{4}$ to $\mathrm{T}_{3}$ [115]. The nuclear sequestration of SECIS binding protein 2 (SBP2), which reduces the incorporation of selenocysteine residues in the selenoproteins [116], might be another mechanism. It is well known that IL-6 induces OS, so that a unifying mechanism might be that cytokineinduced OS alters secondarily the expression and activity of deiodinases [115]. The contribution of the reduction in the levels of thiol cofactor of deiodinases, consequent to the increase in intracellular ROS concentrations, has been suggested by other authors [117].

On the basis of the pathophysiological studies available in the literature, we can conclude that the alterations of the pituitary-thyroid axis depend not only on the severity of the disease, but also on the inflammatory response and the patients' nutritional status. They also indicate that low- $T_{3}$ is simply not an adaptive mechanism, but it is associated with tissue hypothyroidism and OS.

A special, reevaluated role could be played by selenium. This essential trace element exerts complex effects on the endocrine system, due to its antioxidant capacity; it is a cofactor of GPx and Trx reductase (TrxR), enzymes that protect the cells from the oxidative damage [118]. On the other hand, selenium is involved in the mechanisms of deiodination: a proposed model involves the formation of selenenyl iodide intermediate [119], even though the catalytic mechanisms and the regulation of deiodinases by selenium are not fully understood [120]. Thus, because of its double function, molecules that compete with this element could, in a reciprocal way, connect hypothyroidism due to low- $\mathrm{T}_{3}$ and OS. This hypothesis is supported by the evidence that NAC, an antioxidant that restores intracellular GSH levels, prevents the IL-6-induced effects on the intracellular redox state [121, 122]. In addition, the administration of sodium selenite in cells expressing deiodinases decreases the IL-6-induced ROS production and carbonyl protein content and enhances GPx and TrxR activities [123].

Also deiodinases may be involved in NTIS pathophysiology, with possible tissue specificity [124]. DIO1 is a $\mathrm{T}_{3}$-responsive gene; thus, D1 activity and intracellular $\mathrm{T}_{3}$ 


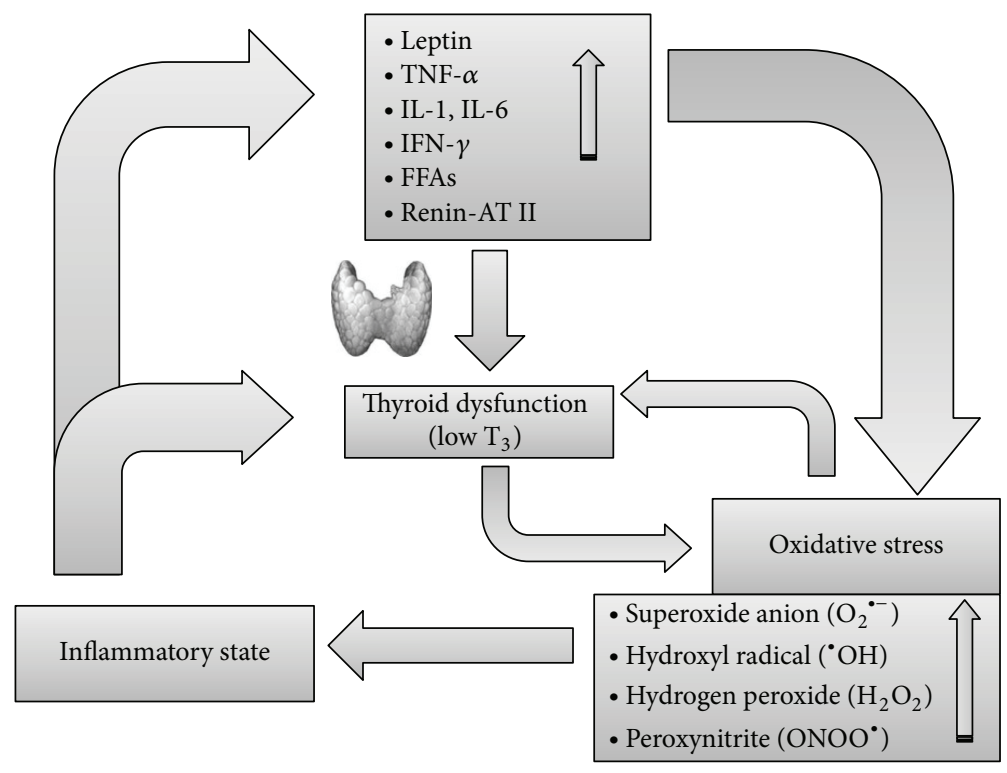

FIGURE 1: Proposed model of the interrelationships between inflammation, oxidative stress, and thyroid derangement. Inflammation, via hormone and cytokine changes, leads to oxidative stress and also affects thyroid function, causing nonthyroidal illness syndrome or pituitarythyroid axis depression. At the tissue level, hypothyroidism reinforces the oxidative stress, which in turn worsens hypothyroidism by inhibiting deiodinases, thus establishing a vicious circle (see text for further explanations). AT: angiotensin; FFAs: free fatty acids; IFN: interferon; IL: interleukin; TNF: tumor necrosis factor.

concentrations can affect each other in a reciprocal way. D1 activity has been shown to be suppressed in hepatocytes. The activity of D2 has been reported to be reduced [125], unchanged [126], or increased [127] in skeletal muscle. An increase in DIO2 expression in skeletal muscle has been reported in mice during chronic inflammation that has been linked to enhanced CREB signaling [128]. On the contrary, skeletal muscle DIO2 expression was found to be decreased in sepsis and this decrease was related to the reduction in food intake [129]. DIO2 expression increases in lung and in endothelial cells following LPS-induced injury [130] and in hepatic resident macrophages during acute and chronic inflammation [128]. As far as D3 is concerned, a decrease in DIO3 mRNA levels has been reported in liver during inflammation and sepsis $[131,132]$. On the contrary, hepatic expression and activity of D3 were found to be increased in rabbits with prolonged critical illness [133]. Similarly, D3 activity was found to be increased in the skeletal muscle of critically ill patients [134] and in patients after myocardial infarction $[135,136]$.

In summary, even if the picture appears to be quite complex, some of these changes are mediated by inflammatory pathways, such as NF-kB and AP-1, whereas the CREB pathway seems to be predominant in skeletal muscle [124]. On the other hand, overexpression of D2 in tanycytes, that has been observed in rats after LPS infusion [117, 137, 138], could be responsible for central suppression of the hypothalamicpituitary-thyroid axis, thereby contributing to the complex picture of the regulation of thyroid function in this clinical condition.

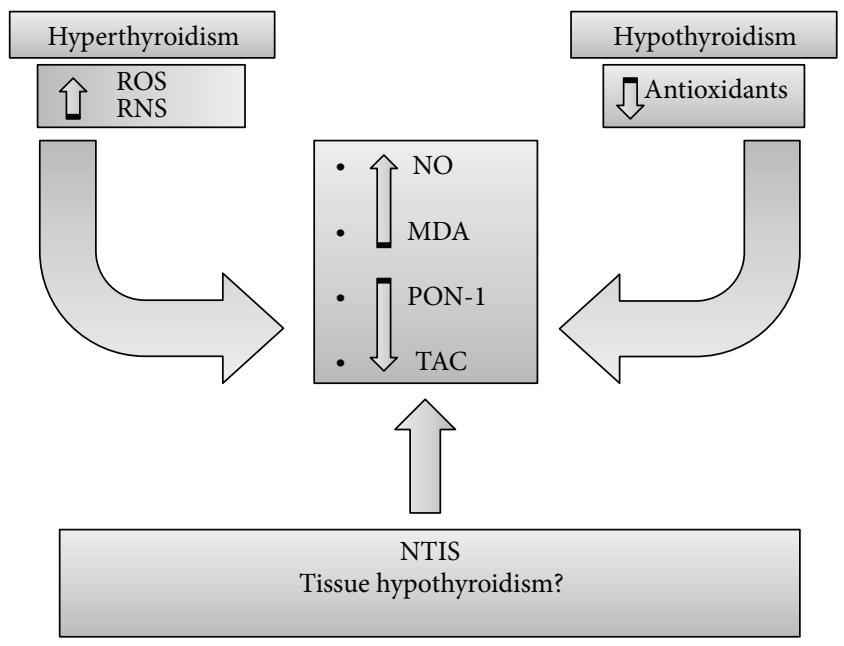

FIGURE 2: Both hyperthyroidism and hypothyroidism can cause oxidative stress but with different mechanisms. We speculate that nonthyroidal illness syndrome (NTIS) may represent a tissue hypothyroidism condition linked to intracellular and systemic oxidative stress. MDA: malondialdehyde; NO: nitric oxide; PON-1: paraoxonase-1; RNS: reactive nitrogen species; ROS: reactive oxygen species; TAC: total antioxidant capacity.

\section{Conclusion}

In conclusion, OS seems to be an important mechanism underlying the progress of inflammation. A vicious circle 
creates a link between these two conditions. Thyroid hormones can have a protective role, modulating antioxidant levels; on the other side, a tissue hypothyroidism can worsen OS (Figure 1). An interesting model is represented by NTIS, in which IL production due to inflammation can reduce the expression of deiodinases, inducing low- $\mathrm{T}_{3}$ levels and consequently a condition of tissue hypothyroidism. In turn, this latter could cause further OS (Figure 2). These pathophysiological observations suggest the possible therapeutic efficacy of antioxidants in the NTIS.

\section{Conflict of Interests}

The authors declare that there is no conflict of interests regarding the publication of this paper.

\section{References}

[1] J. R. Lancaster, "Nitric oxide in cells," American Scientist, vol. 80, pp. 249-259, 1992.

[2] G. P. Littarru, Energy and Defence, CESI, Roma, Italy, 1994.

[3] D. Kang and N. Hamasaki, "Mitochondrial oxidative stress and mitochondrial DNA," Clinical Chemistry and Laboratory Medicine, vol. 41, no. 10, pp. 1281-1288, 2003.

[4] M. Valko, D. Leibfritz, J. Moncol, M. T. D. Cronin, M. Mazur, and J. Telser, "Free radicals and antioxidants in normal physiological functions and human disease," International Journal of Biochemistry \& Cell Biology, vol. 39, no. 1, pp. 44-84, 2007.

[5] D. A. Wink, H. B. Hines, R. Y. S. Cheng et al., "Nitric oxide and redox mechanisms in the immune response," Journal of Leukocyte Biology, vol. 89, no. 6, pp. 873-891, 2011.

[6] M. Le Bras, M.-V. Clément, S. Pervaiz, and C. Brenner, "Reactive oxygen species and the mitochondrial signaling pathway of cell death," Histology and Histopathology, vol. 20, no. 1, pp. 205-220, 2005.

[7] H. Mangge, K. Becker, D. Fuchs, and J. M. Gostner, "Antioxidants, inflammation and cardiovascular disease," World Journal of Cardiology, vol. 6, no. 6, pp. 462-477, 2014.

[8] B. Halliwell and J. M. C. Gutteridge, Free Radical in Biology and Medicine, Clarendon Press, Oxford, UK, 2nd edition, 1979.

[9] A. R. Cross and O. T. G. Jones, "Enzymic mechanism of superoxyde production," Biochimica and Biophysica Acta, vol. 1057, pp. 281-284, 1991.

[10] H. Ohye and M. Sugawara, "Dual oxidase, hydrogen peroxide and thyroid diseases," Experimental Biology and Medicine, vol. 235, no. 4, pp. 424-433, 2010.

[11] V. Varela, C. M. Rivolta, S. A. Esperante, L. GruneiroPapendieck, A. Chiesa, and H. M. Targovnik, "Three mutations (p.Q36H, p.G418fsX482, and g.IVS19-2A>C) in the dual oxidase 2 gene responsible for congenital goiter and iodide organification defect," Clinical Chemistry, vol. 52, no. 2, pp. 182191, 2006.

[12] J. F. Turrens and A. Boveris, "Generation of superoxyde anion by the NADH dehydrogenase of bovine mitochondria," The Biochemical Journal, vol. 191, pp. 421-427, 1980.

[13] S. P. Wolff, Z. Y. Jiang, and J. V. Hunt, "Protein glycation and oxidative stress in diabetes mellitus and ageing," Free Radical Biology \& Medicine, vol. 10, no. 5, pp. 339-352, 1991.

[14] P. Codoñer-Franch, V. Valls-Bellés, A. Arilla-Codoñer, and E. Alonso-Iglesias, "Oxidant mechanisms in childhood obesity: the link between inflammation and oxidative stress," Translational Research, vol. 158, no. 6, pp. 369-384, 2011.

[15] M. B. Zimmermann and I. Aeberli, "Dietary determinants of subclinical inflammation, dyslipidemia and components of the metabolic syndrome in overweight children: a review," International Journal of Obesity, vol. 32, supplement 6, pp. S11S18, 2008.

[16] H. N. Siti, Y. Kamisah, and J. Kamsiah, "The role of oxidative stress, antioxidants and vascular inflammation in cardiovascular disease (a review)," Vascular Pharmacology, vol. 71, pp. 4056, 2015.

[17] I. J. Chopra, "Euthyroid sick syndrome: is it a misnomer?" The Journal of Clinical Endocrinology and Metabolism, vol. 82, no. 2, pp. 329-334, 1997.

[18] L. J. De Groot, "Non-thyroidal illness syndrome is a manifestation of hypothalamic-pituitary dysfunction, and in view of current evidence, should be treated with appropriate replacement therapies," Critical Care Clinics, vol. 22, no. 1, pp. 57-86, 2006.

[19] A. Mancini, S. Raimondo, C. Di Segni, M. Persano, and A. Pontecorvi, "Non-thyroidal illness: physiopathology and clinical implications," in Current Topics in Hypothyroidism with Focus on Development, E. Potlukova, Ed., pp. 183-202, InTech, Rijeka, Croatia, 2013.

[20] M. F. Gregor and G. S. Hotamisligil, "Adipocyte stress: the endoplasmic reticulum and metabolic disease," Journal of Lipid Research, vol. 48, no. 9, pp. 1905-1914, 2007.

[21] S. P. Weisberg, D. McCann, M. Desai, M. Rosenbaum, R. L. Leibel, and A. W. Ferrante Jr., "Obesity is associated with macrophage accumulation in adipose tissue," The Journal of Clinical Investigation, vol. 112, no. 12, pp. 1796-1808, 2003.

[22] A. Sorisky, A. S. D. Molgat, and A. Gagnon, "Macrophageinduced adipose tissue dysfunction and the preadipocyte: should I stay (and differentiate) or should I go?" Advances in Nutrition, vol. 4, no. 1, pp. 67-75, 2013.

[23] A. Iyer, D. P. Fairlie, J. B. Prins, B. D. Hammock, and L. Brown, "Inflammatory lipid mediators in adipocyte function and obesity," Nature Reviews Endocrinology, vol. 6, no. 2, pp. 71$82,2010$.

[24] T. Barhoumi, M. Briet, D. A. Kasal et al., "Erythropoietininduced hypertension and vascular injury in mice overexpressing human endothelin-1: exercise attenuated hypertension, oxidative stress, inflammation and immune response," Journal of Hypertension, vol. 32, no. 4, pp. 784-794, 2014.

[25] X.-F. Leong, M. N. M. Najib, S. Das, M. R. Mustafa, and K. Jaarin, "Intake of repeatedly heated palm oil causes elevation in blood pressure with impaired vasorelaxation in rats," The Tohoku Journal of Experimental Medicine, vol. 219, no. 1, pp. 7178, 2009.

[26] S. Yamamoto, S. Shimizu, S. Kiyonaka et al., "TRPM2-mediated $\mathrm{Ca}^{2+}$ influx induces chemokine production in monocytes that aggravates inflammatory neutrophil infiltration," Nature Medicine, vol. 14, no. 7, pp. 738-747, 2008.

[27] S.-H. Ko, W. Cao, and Z. Liu, "Hypertension management and microvascular insulin resistance in diabetes," Current Hypertension Reports, vol. 12, no. 4, pp. 243-251, 2010.

[28] G. Li, E. J. Barrett, M. O. Barrett, W. Cao, and Z. Liu, "Tumor necrosis factor- $\alpha$ induces insulin resistance in endothelial cells via a p38 mitogen-activated protein kinase-dependent pathway," Endocrinology, vol. 148, no. 7, pp. 3356-3363, 2007.

[29] Z. Liu, J. Liu, L. A. Jahn, D. E. Fowler, and E. J. Barrett, “Infusing lipid raises plasma free fatty acids and induces insulin resistance 
in muscle microvasculature," Journal of Clinical Endocrinology \& Metabolism, vol. 94, no. 9, pp. 3543-3549, 2009.

[30] L. H. Clerk, S. Rattigan, and M. G. Clark, "Lipid infusion impairs physiologic insulin-mediated capillary recruitment and muscle glucose uptake in vivo," Diabetes, vol. 51, no. 4, pp. 11381145, 2002.

[31] D. Tripathy, P. Mohanty, S. Dhindsa et al., "Elevation of free fatty acids induces inflammation and impairs vascular reactivity in healthy subjects," Diabetes, vol. 52, no. 12, pp. 2882-2887, 2003.

[32] H. O. Steinberg, G. Paradisi, G. Hook, K. Crowder, J. Cronin, and A. D. Baron, "Free fatty acid elevation impairs insulinmediated vasodilation and nitric oxide production," Diabetes, vol. 49, no. 7, pp. 1231-1238, 2000.

[33] A. Mancini, G. E. Martorana, M. Magini et al., "Oxidative stress and metabolic syndrome: effects of a natural antioxidants enriched diet on insulin resistance," Clinical Nutrition ESPEN, vol. 10, no. 2, pp. e52-e60, 2015.

[34] C.-Y. Ng, Y. Kamisah, O. Faizah, and K. Jaarin, "The role of repeatedly heated soybean oil in the development of hypertension in rats: association with vascular inflammation," International Journal of Experimental Pathology, vol. 93, no. 5, pp. 377387, 2012.

[35] S. Ryoo, A. Bhunia, F. Chang, A. Shoukas, D. E. Berkowitz, and L. H. Romer, "OxLDL-dependent activation of arginase II is dependent on the LOX-1 receptor and downstream RhoA signaling," Atherosclerosis, vol. 214, no. 2, pp. 279-287, 2011.

[36] A. Pirillo, G. D. Norata, and A. L. Catapano, "LOX-1, OxLDL, and atherosclerosis," Mediators of Inflammation, vol. 2013, Article ID 152786, 12 pages, 2013.

[37] K. Husain, W. Hernandez, R. A. Ansari, and L. Ferder, "Inflammation, oxidative stress and renin angiotensin system in atherosclerosis," World Journal of Biological Chemisty, vol. 6, no. 3, pp. 209-217, 2015.

[38] K. Husain, E. Suarez, A. Isidro, and L. Ferder, "Effects of paricalcitol and enalapril on atherosclerotic injury in mouse aortas," American Journal of Nephrology, vol. 32, no. 4, pp. 296304, 2010.

[39] E. Suarez-Martinez, K. Husain, and L. Ferder, "Adiponectin expression and the cardioprotective role of the vitamin $\mathrm{D}$ receptor activator paricalcitol and the angiotensin converting enzyme inhibitor enalapril in ApoE-deficient mice," Therapeutic Advances in Cardiovascular Disease, vol. 8, no. 6, pp. 224-236, 2015.

[40] P. Lewis, N. Stefanovic, J. Pete et al., "Lack of the antioxidant enzyme glutathione peroxidase-1 accelerates atherosclerosis in diabetic apolipoprotein E-deficient mice," Circulation, vol. 115, no. 16, pp. 2178-2187, 2007.

[41] A. Mancini, E. Giacchi, S. Raimondo, C. Di Segni, A. Silvestrini, and E. Meucci, "Hypothyroidism, oxidative stress and reproduction," in Hypothyroidism-Influences and Treatments, pp. 117-134, InTech, Rijeka, Croatia, 2012.

[42] U. Resch, G. Helsel, F. Tatzber, and H. Sinzinger, "Antioxidant status in thyroid dysfunction," Clinical Chemistry and Laboratory Medicine, vol. 40, no. 11, pp. 1132-1134, 2002.

[43] K. Asayama and K. Kato, "Oxidative muscular injury and its relevance to hyperthyroidism," Free Radical Biology and Medicine, vol. 8, no. 3, pp. 293-303, 1990.

[44] M. M. Dobrzyńska, A. Baumgartner, and D. Anderson, "Antioxidants modulate thyroid hormone- and noradrenaline-induced DNA damage in human sperm," Mutagenesis, vol. 19, no. 4, pp. 325-330, 2004.
[45] P. Venditti and S. Di Meo, "Thyroid hormone-induced oxidative stress," Cellular and Molecular Life Sciences, vol. 63, no. 4, pp. 414-434, 2006.

[46] A. J. Kowaltowski, A. D. T. Costa, and A. E. Vercesi, "Activation of the potato plant uncoupling mitochondrial protein inhibits reactive oxygen species generation by the respiratory chain," FEBS Letters, vol. 425, no. 2, pp. 213-216, 1998.

[47] L. Rebiger, S. Lenzen, and I. Mehmeti, "Susceptibility of brown adipocytes to pro-inflammatory cytokine toxicity and reactive oxygen species," Bioscience Reports, 2016.

[48] T. Hoang, M. Kuljanin, M. D. Smith, and M. Jelokhani-Niaraki, "A biophysical study on molecular physiology of the uncoupling proteins of the central nervous system," Bioscience Reports, vol. 35, no. 4, Article ID e00226, 2015.

[49] N. Potrović, G. Cvijić, and V. Davidović, "Thyroxine and triiodothyronine differently affect uncoupling protein-1 content and antioxidant enzyme activities in rat interscapular brown adipose tissue," Journal of Endocrinology, vol. 176, no. 1, pp. 3138, 2003.

[50] M. Branco, M. Ribeiro, N. Negrão, and A. C. Bianco, " $3,5,3$ ' -triiodothyronine actively stimulates UCP in brown fat under minimal sympathetic activity," The American Journal of Physiology-Endocrinology and Metabolism, vol. 276, no. 1, pp. E179-E187, 1999.

[51] S. Hima and S. Sreeja, "Regulatory role of estrogen-induced reactive oxygen species in the modulatory function of UCP 2 in papillary thyroid cancer cells," IUBMB Life, vol. 67, no. 11, pp. 837-846, 2015.

[52] P. Venditti, L. Di Stefano, and S. Di Meo, "Vitamin E management of oxidative damage-linked dysfunctions of hyperthyroid tissues," Cellular and Molecular Life Sciences, vol. 70, no. 17, pp. 3125-3144, 2013.

[53] P. Venditti, M. Balestrieri, S. Di Meo, and T. De Leo, "Effect of thyroid state on lipid peroxidation, antioxidant defences, and susceptibility to oxidative stress in rat tissues," Journal of Endocrinology, vol. 155, no. 1, pp. 151-157, 1997.

[54] V. Fernandez, X. Barrientos, K. Kipreos, A. Valenzuela, and L. A. Videla, "Superoxide radical generation, NADPH oxidase activity, and cytochrome P-450 content of rat liver microsomal fractions in an experimental hyperthyroid state: relation to lipid peroxidation," Endocrinology, vol. 117, no. 2, pp. 496-501, 1985.

[55] P. Venditti, M. C. Daniele, P. Masullo, and S. Di Meo, "Antioxidant-sensitive triiodothyronine effects on characteristics of rat liver mitochondrial population," Cellular Physiology and Biochemistry, vol. 9, no. 1, pp. 38-52, 1999.

[56] K. Huh, T.-H. Kwon, J.-S. Kim, and J. M. Park, "Role of the hepatic xanthine oxidase in thyroid dysfunction: effect of thyroid hormones in oxidative stress in rat liver," Archives of Pharmacal Research, vol. 21, no. 3, pp. 236-240, 1998.

[57] K. Asayama, K. Dobashi, H. Hayashibe, Y. Megata, and K. Kato, "Lipid peroxidation and free radical scavengers in thyroid dysfunction in the rat: a possible mechanism of injury to heart and skeletal muscle in hyperthyroidism," Endocrinology, vol. 121, no. 6, pp. 2112-2118, 1987.

[58] S. Choudhury, G. B. N. Chainy, and M. M. Mishro, "Experimentally induced hypo- and hyper-thyroidism influence on the antioxidant defence system in adult rat testis," Andrologia, vol. 35, no. 3, pp. 131-140, 2003.

[59] E. Ademoğlu, C. Gökkuşu, S. Yarman, and H. Azizlerli, “The effect of methimazole on the oxidant and antioxidant system in patients with hyperthyroidism," Pharmacological Research, vol. 38, no. 2, pp. 93-96, 1998. 
[60] G. Bianchi, E. Solaroli, V. Zaccheroni et al., "Oxidative stress and anti-oxidant metabolites in patients with hyperthyroidism: effect of treatment," Hormone and Metabolic Research, vol. 31, no. 11, pp. 620-624, 1999.

[61] A. Mancini, L. De Marinis, F. Calabrò, C. Fiumara, A. Goglia, and G. P. Littarru, "Physiopathological relevance of coenzyme Q10 in thyroid disorders: CoQ10 concentrations in normal and diseased human thyroid tissue," in Biomedical and Clinical Aspects of Coenzyme Q, K. Folkers, G. P. Littarru, and T. Yamagami, Eds., vol. 6, pp. 441-448, Elsevier Science Publisher, Amsterdam, The Netherlands, 1991.

[62] A. Mancini, L. De Marinis, F. Calabrò et al., "Evaluation of metabolic status in amiodarone-induced thyroid disorders: plasma coenzyme Q10 determination," Journal of Endocrinological Investigation, vol. 12, no. 8, pp. 511-516, 1989.

[63] A. Mancini, G. M. Corbo, A. Gaballo et al., "Relationships between plasma CoQ10 levels and thyroid hormones in chronic obstructive pulmonary disease," BioFactors, vol. 25, no. 1-4, pp. 201-204, 2005.

[64] G. Baskol, H. Atmaca, F. Tanriverdi, M. Baskol, D. Kocer, and F. Bayram, "Oxidative stress and enzymatic antioxidant status in patients with hypothyroidism before and after treatment," Experimental and Clinical Endocrinology \& Diabetes, vol. 115, no. 8, pp. 522-526, 2007.

[65] A. N. Torun, S. Kulaksizoglu, M. Kulaksizoglu, B. O. Pamuk, E. Isbilen, and N. B. Tutuncu, "Serum total antioxidant status and lipid peroxidation marker malondialdehyde levels in overt and subclinical hypothyroidism," Clinical Endocrinology, vol. 70, no. 3, pp. 469-474, 2009.

[66] A. Dardano, L. Ghiadoni, Y. Plantinga et al., "Recombinant human thyrotropin reduces endothelium-dependent vasodilation in patients monitored for differentiated thyroid carcinoma," Journal of Clinical Endocrinology \& Metabolism, vol. 91, no. 10, pp. 4175-4178, 2006.

[67] A. Haribabu, V. S. Reddy, C. Pallavi et al., "Evaluation of protein oxidation and its association with lipid peroxidation and thyrotropin levels in overt and subclinical hypothyroidism," Endocrine, vol. 44, no. 1, pp. 152-157, 2013.

[68] M. J. Coria, A. I. Pastrán, and M. S. Gimenez, "Serum oxidative stress parameters of women with hypothyroidism," Acta Biomedica Atenei Parmensis, vol. 80, pp. 135-139, 2009.

[69] H. Erdamar, H. Demirci, H. Yaman et al., "The effect of hypothyroidism, hyperthyroidism, and their treatment on parameters of oxidative stress and antioxidant status," Clinical Chemistry and Laboratory Medicine, vol. 46, no. 7, pp. 1004-1010, 2008.

[70] F. Azizi, F. Raiszadeh, M. Solati, A. Etemadi, M. Rahmani, and M. Arabi, "Serum paraoxonase 1 activity is decreased in thyroid dysfunction," Journal of Endocrinological Investigation, vol. 26, no. 8, pp. 703-709, 2003.

[71] A. Santi, M. M. M. F. Duarte, R. N. Moresco et al., "Association between thyroid hormones, lipids and oxidative stress biomarkers in overt hypothyroidism," Clinical Chemistry and Laboratory Medicine, vol. 48, no. 11, pp. 1635-1639, 2010.

[72] N. Nanda, Z. Bobby, A. Hamide, B. C. Koner, and M. G. Sridhar, "Association between oxidative stress and coronary lipid risk factors in hypothyroid women is independent of body mass index," Metabolism, vol. 56, no. 10, pp. 1350-1355, 2007.

[73] L. Kebapcilar, B. Akinci, F. Bayraktar et al., "Plasma thiobarbituric acid-reactive substance levels in subclinical hypothyroidism," Medical Principles and Practice, vol. 16, no. 6, pp. 432436, 2007.
[74] A. Santi, M. M. M. F. Duarte, C. C. de Menezes, and V. L. Loro, "Association of lipids with oxidative stress biomarkers in subclinical hypothyroidism," International Journal of Endocrinology, vol. 2012, Article ID 856359, 7 pages, 2012.

[75] A. Mancini, R. Festa, V. Di Donna et al., "Hormones and antioxidant systems: role of pituitary and pituitary-dependent axes," Journal of Endocrinological Investigation, vol. 33, no. 6, pp. 422-433, 2010.

[76] A. Mancini, E. Leone, A. Silvestrini et al., "Evaluation of antioxidant systems in pituitary-adrenal axis diseases," Pituitary, vol. 13, no. 2, pp. 138-145, 2010.

[77] U. Weyemi, B. Caillou, M. Talbot et al., "Intracellular expression of reactive oxygen species-generating NADPH oxidase NOX4 in normal and cancer thyroid tissues," Endocrine-Related Cancer, vol. 17, no. 1, pp. 27-37, 2010.

[78] R. Sharma, K. Traore, M. A. Trush, N. R. Rose, and C. L. Burek, "Intracellular adhesion molecule-1 up-regulation on thyrocytes by iodine of non-obese diabetic.H2h4 mice is reactive oxygen species-dependent," Clinical and Experimental Immunology, vol. 152, no. 1, pp. 13-20, 2008.

[79] Ü. Öztürk, P. Vural, A. Özderya, B. Karadağ, S. DoğruAbbasoğlu, and M. Uysal, "Oxidative stress parameters in serum and low density lipoproteins of Hashimoto's thyroiditis patients with subclinical and overt hypothyroidism," International Immunopharmacology, vol. 14, no. 4, pp. 349-352, 2012.

[80] A. S. da Rosa Araujo, M. F. Silva de Miranda, U. O. de Oliveira et al., "Increased resistance to hydrogen peroxide-induced cardiac contracture is associated with decreased myocardial oxidative stress in hypothyroid rats," Cell Biochemistry and Function, vol. 28, no. 1, pp. 38-44, 2010.

[81] M. M. Estévez-Carmona, E. Meléndez-Camargo, R. OrtizButron, M. Pineda-Reynoso, M. Franco-Colin, and E. CanoEuropa, "Hypothyroidism maintained reactive oxygen speciessteady state in the kidney of rats intoxicated with ethylene glycol: effect related to an increase in the glutathione that maintains the redox environment," Toxicology and Industrial Health, vol. 29, no. 6, pp. 555-566, 2013.

[82] E. Cano-Europa, F. Pérez-Severiano, P. Vergara et al., "Hypothyroidism induces selective oxidative stress in amygdala and hippocampus of rat," Metabolic Brain Disease, vol. 23, no. 3, pp. 275-287, 2008.

[83] T. Pan, M. Zhong, X. Zhong, Y. Zhang, and D. Zhu, "Levothyroxine replacement therapy with vitamin E supplementation prevents oxidative stress and cognitive deficit in experimental hypothyroidism," Endocrine, vol. 43, no. 2, pp. 434-439, 2013.

[84] E. Cano-Europa, V. Blas-Valdivia, M. Franco-Colin, C. A. Gallardo-Casas, and R. Ortiz-Butrón, "Methimazole-induced hypothyroidism causes cellular damage in the spleen, heart, liver, lung and kidney," Acta Histochemica, vol. 113, no. 1, pp. 1-5, 2011.

[85] R. Ortiz-Butron, V. Blas-Valdivia, M. Franco-Colin, M. PinedaReynoso, and E. Cano-Europa, "An increase of oxidative stress markers and the alteration of the antioxidant enzymatic system are associated with spleen damage caused by methimazoleinduced hypothyroidism," Drug and Chemical Toxicology, vol. 34, no. 2, pp. 180-188, 2011.

[86] E. Cano-Europa, V. Blas-Valdivia, G. E. Lopez-Galindo et al., "Methimazole-induced hypothyroidism causes alteration of the REDOX environment, oxidative stress, and hepatic damage; events not caused by hypothyroidism itself," Annals of Hepatology, vol. 9, no. 1, pp. 80-88, 2010. 
[87] I. Klein and S. Danzi, “Thyroid disease and the heart," Circulation, vol. 116, no. 15, pp. 1725-1735, 2007.

[88] M. T. Elnakish, A. A. E. Ahmed, P. J. Mohler, and P. M. Janssen, "Role of oxidative stress in thyroid hormone-induced cardiomyocyte hypertrophy and associated cardiac dysfunction: an undisclosed story," Oxidative Medicine and Cellular Longevity, vol. 2015, Article ID 854265, 16 pages, 2015.

[89] M. O. Akiibinu, O. A. Ogundahunsi, and E. O. Ogunyemi, "Inter-relationship of plasma markers of oxidative stress and thyroid hormones in schizophrenics," BMC Research Notes, vol. 5, article 169, 2012.

[90] N. Zhang, L. Wang, Q. Duan et al., "Metallothionein-I/II knockout mice aggravate mitochondrial superoxide production and peroxiredoxin 3 expression in thyroid after excessive iodide exposure," Oxidative Medicine and Cellular Longevity, vol. 2015, Article ID 267027, 11 pages, 2015.

[91] M. Vitale, T. Di Matola, F. D’Ascoli et al., "Iodide excess induces apoptosis in thyroid cells through a p53-independent mechanism involving oxidative stress," Endocrinology, vol. 141, no. 2, pp. 598-605, 2000.

[92] B. Corvilain, L. Collyn, J. van Sande, and J. E. Dumont, "Stimulation by iodide of $\mathrm{H}_{2} \mathrm{O}_{2}$ generation in thyroid slices from several species," American Journal of Physiology -Endocrinology and Metabolism, vol. 278, no. 4, pp. E692-E699, 2000.

[93] A. M. Y. Shum and P. Polly, "Cancer cachexia: molecular targets and pathways for diagnosis and drug intervention," Endocrine, Metabolic \& Immune Disorders-Drug Targets, vol. 12, no. 3, pp. 247-259, 2012.

[94] Y.-P. Li, R. J. Schwartz, I. D. Waddell, B. R. Holloway, and M. B. Reid, "Skeletal muscle myocytes undergo protein loss and reactive oxygen-mediated NF- $\kappa \mathrm{B}$ activation in response to tumor necrosis factor $\alpha$, "The FASEB Journal, vol. 12, no. 10, pp. 871-880, 1998.

[95] S. T. Russell, H. Eley, and M. J. Tisdale, "Role of reactive oxygen species in protein degradation in murine myotubes induced by proteolysis-inducing factor and angiotensin II," Cellular Signalling, vol. 19, no. 8, pp. 1797-1806, 2007.

[96] H. Suzuki, A. Asakawa, H. Amitani, N. Nakamura, and A. Inui, "Cancer cachexia-pathophysiology and management," Journal of Gastroenterology, vol. 48, no. 5, pp. 574-594, 2013.

[97] H. Mönig, T. Arendt, M. Meyer, S. Kloehn, and B. Bewig, "Activation of the hypothalamo-pituitary-adrenal axis in response to septic or non-septic diseases-implications for the enthyroid sick syndrome," Intensive Care Medicine, vol. 25, no. 12, pp. 1402-1406, 1999.

[98] A. R. M. M. Hermus, C. G. J. Sweep, M. J. M. Van Der et al., "Continuous infusion of interleukin-1 induces a nonthyroidal illness syndrome in the rat," Endocrinology, vol. 131, pp. 21392146, 1992.

[99] T. Van der Poll, J. A. Romijn, W. M. Wiersinga, and H. P. Sauerwein, "Tumor necrosis factor: a putative mediator of the sick euthyroid syndrome in man," Journal of Clinical Endocrinology \& Metabolism, vol. 71, no. 6, pp. 1567-1572, 1990.

[100] T. Van der Poll, E. Endert, S. M. Coyle, J. M. Agosti, and S. F. Lowry, "Neutralization of TNF does not influence endotoxin induced changes in thyroid hormone metabolism in humans," American Journal of Physiology, vol. 276, no. 2, part 2, pp. R357R362, 1999.

[101] T. Nagaya, M. Fujieda, G. Otsuka, J.-P. Yang, T. Okamoto, and H. Seo, "A potential role of activated NF- $\kappa$ B in the pathogenesis of euthyroid sick syndrome," The Journal of Clinical Investigation, vol. 106, no. 3, pp. 393-402, 2000.
[102] L. Bartalena, S. Brogioni, L. Grasso, F. Velluzzi, and E. Martino, "Relationship of the increased serum interleukin-6 concentration to changes of thyroid function in nonthyroidal illness," Journal of Endocrinological Investigation, vol. 17, no. 4, pp. 269274, 1994.

[103] A. Boelen, M. C. Platvoet-Ter Schiphorst, and W. M. Wiersinga, "Association between serum interleukin-6 and serum 3,5,3' triiodothyronine in nonthyroidal illness," Journal of Clinical Endocrinology and Metabolism, vol. 77, no. 6, pp. 1695-1699, 1993.

[104] J. M. L. Stouthard, T. Van Der Poll, E. Endert et al., "Effects of acute and chronic interleukin- 6 administration on thyroid hormone metabolism in humans," Journal of Clinical Endocrinology and Metabolism, vol. 79, no. 5, pp. 1342-1346, 1994.

[105] B. Gereben, A. M. Zavacki, S. Ribich et al., "Cellular and molecular basis of deiodinase-regulated thyroid hormone signaling," Endocrine Reviews, vol. 29, no. 7, pp. 898-938, 2008.

[106] A. Orozco, R. C. Valverde, A. Olvera, and G. C. García, "Iodothyronine deiodinases: a functional and evolutionary perspective," Journal of Endocrinology, vol. 215, no. 2, pp. 207219,2012

[107] D. L. St Germain, V. A. Galton, and A. Hernandez, "Miniereview: defining the roles of the iodothyronine deiodinases: current concepts and challenges," Endocrinology, vol. 150, no. 3, pp. 1097-1107, 2009.

[108] U. Schweizer and C. Steegborn, "New insights into the structure and mechanism of iodothyronine deiodinases," Journal of Molecular Endocrinology, vol. 55, no. 3, pp. R37-R52, 2015.

[109] R. Arrojo E Drigo and A. C. Bianco, "Type 2 deiodinase at the crossroads of thyroid hormone action," The International Journal of Biochemistry \& Cell Biology, vol. 43, no. 10, pp. 14321441, 2011.

[110] A. C. Bianco and B. W. Kim, "Deiodinases: implications of the local control of thyroid hormone action," The Journal of Clinical Investigation, vol. 116, no. 10, pp. 2571-2579, 2006.

[111] M. Watanabe, S. M. Houten, C. Mataki et al., "Bile acids induce energy expenditure by promoting intracellular thyroid hormone activation," Nature, vol. 439, no. 7075, pp. 484-489, 2006.

[112] S. M. Wajner, I. M. Goemann, A. L. Bueno, P. R. Larsen, and A. L. Maia, "IL-6 promotes nonthyroidal illness syndrome by blocking thyroxine activation while promoting thyroid hormone inactivation in human cells," The Journal of Clinical Investigation, vol. 121, no. 5, pp. 1834-1845, 2011.

[113] A. Mancini, E. Leone, V. Di Donna, and R. Festa, "Anorexia nervosa and cytokines," in Anorexia Nervosa: A Multidisciplinary Approach, A. Mancini, S. Daini, and L. Caruana, Eds., pp. 3149, Nova Science Publishers, New York, NY, USA, 2010.

[114] J. Abilés, A. P. de la Cruz, J. Castaño et al., "Oxidative stress is increased in critically ill patients according to antioxidant vitamins intake, independent of severity: a cohort study," Critical Care, vol. 10, no. 5, article R146, 2006.

[115] A. L. Maia, B. W. Kim, S. A. Huang, J. W. Harney, and P. R. Larsen, "Type 2 iodothyronine deiodinase is the major source of plasma T3 in euthyroid humans," The Journal of Clinical Investigation, vol. 115, no. 9, pp. 2524-2533, 2005.

[116] L. V. Papp, J. Lu, F. Striebel, D. Kennedy, A. Holmgren, and K. K. Khanna, "The redox state of SECIS binding protein 2 controls its localization and selenocysteine incorporation function," Molecular and Cellular Biology, vol. 26, no. 13, pp. 4895-4910, 2006. 
[117] A. Marsili, A. M. Zavacki, J. W. Harney, and P. R. Larsen, "Physiological role and regulation of iodothyronine deiodinases: a 2011 update," Journal of Endocrinological Investigation, vol. 34, no. 5, pp. 395-407, 2011.

[118] C. Balasz and K. Racz, "The role of selenium in endocrine system disease," Orvosi Hetilap (Hungaria), vol. 154, no. 41, pp. 1628-1635, 2013.

[119] G. G. J. M. Kuiper, M. H. A. Kester, R. P. Peeters, and T. J. Visser, "Biochemical mechanisms of thyroid hormone deiodination," Thyroid, vol. 15, no. 8, pp. 787-798, 2005.

[120] U. Schweizer and C. Steegborn, "New insights into the structure and mechanism of iodothyronine deiodinases," Journal of Molecular Endocrinology, vol. 55, no. 3, pp. R37-R52, 2015.

[121] S. M. Wajner, I. M. Goemann, A. L. Bueno, P. R. Larsen, and A. L. Maia, "IL-6 promotes nonthyroidal illness syndrome by blocking thyroxine activation while promoting thyroid hormone inactivation in human cells," Journal of Clinical Investigation, vol. 121, no. 5, pp. 1834-1845, 2011.

[122] J. Vidart, S. M. Wajner, R. S. Leite et al., "N-acetylcysteine administration prevents nonthyroidal illness syndrome in patients with acute myocardial infarction: a randomized clinical trial," Journal of Clinical Endocrinology \& Metabolism, vol. 99, no. 12, pp. 4537-4545, 2014.

[123] S. M. Wajner, H. C. Rohenkohl, T. Serrano, and A. L. Maia, "Sodium selenite supplementation does not fully restore oxidative stress-induced deiodinase dysfunction: implications for the nonthyroidal illness syndrome," Redox Biology, vol. 6, pp. 436445, 2015.

[124] E. M. de Vries, E. Fliers, and A. Boelen, "The molecular basis of the non-thyroidal illness syndrome," Journal of Endocrinology, vol. 225, no. 3, pp. R67-R81, 2015.

[125] R. P. Peeters, P. J. Wouters, H. Van Toor, E. Kaptein, T. J. Visser, and G. Van Den Berghe, "Serum 3,3',5' -triiodothyronine (rT3) and 3,5,3' -triiodothyronine/rT3 are prognostic markers in critically ill patients and are associated with postmortem tissue deiodinase activities," Journal of Clinical Endocrinology and Metabolism, vol. 90, no. 8, pp. 4559-4565, 2005.

[126] A. Rodriguez-Perez, F. Palos-Paz, E. Kaptein et al., "Identification of molecular mechanisms related to nonthyroidal illness syndrome in skeletal muscle and adipose tissue from patients with septic shock," Clinical Endocrinology, vol. 68, no. 5, pp. 821827, 2008.

[127] L. Mebis, L. Langouche, T. J. Visser, and G. Van den Berghe, "The type II iodothyronine deiodinase is upregulated in skeletal muscle during prolonged critical illness," The Journal of Clinical Endocrinology \& Metabolism, vol. 92, no. 8, pp. 3330-3333, 2007.

[128] J. Kwakkel, O. V. Surovtseva, E. M. de Vries, J. Stap, E. Fliers, and A. Boelen, "A novel role for the thyroid hormone-activating enzyme type 2 deiodinase in the inflammatory response of macrophages," Endocrinology, vol. 155, no. 7, pp. 2725-2734, 2014.

[129] K. A. Heemstra, M. R. Soeters, E. Fliers et al., "Type 2 iodothyronine deiodinase in skeletal muscle: effects of hypothyroidism and fasting," Journal of Clinical Endocrinology \& Metabolism, vol. 94, no. 6, pp. 2144-2150, 2009.

[130] S.-F. Ma, L. Xie, M. Pino-Yanes et al., "Type 2 deiodinase and host responses of sepsis and acute lung injury," American Journal of Respiratory Cell and Molecular Biology, vol. 45, no. 6, pp. 1203-1211, 2011.

[131] A. Boelen, J. Kwakkel, A. Alkemade et al., "Induction of type 3 deiodinase activity in inflammatory cells of mice with chronic local inflammation," Endocrinology, vol. 146, no. 12, pp. 51285134,2005

[132] A. Boelen, J. Kwakkel, W. M. Wiersinga, and E. Fliers, "Chronic local inflammation in mice results in decreased TRH and type 3 deiodinase mRNA expression in the hypothalamic paraventricular nucleus independently of diminished food intake," Journal of Endocrinology, vol. 191, no. 3, pp. 707-714, 2006.

[133] Y. Debaveye, B. Ellger, L. Mebis et al., "Tissue deiodinase activity during prolonged critical illness: effects of exogenous thyrotropin-releasing hormone and its combination with growth hormone-releasing peptide-2," Endocrinology, vol. 146, no. 12, pp. 5604-5611, 2005.

[134] R. P. Peeters, P. J. Wouters, E. Kaptein, H. van Toor, T. J. Visser, and G. Van Den Berghe, "Reduced activation and increased inactivation of thyroid hormone in tissues of critically ill patients," Journal of Clinical Endocrinology \& Metabolism, vol. 88, no. 7, pp. 3202-3211, 2003.

[135] F. W. J. S. Wassen, A. E. Schiel, G. G. J. M. Kuiper et al., "Induction of thyroid hormone-degrading deiodinase in cardiac hypertrophy and failure," Endocrinology, vol. 143, no. 7, pp. 2812-2815, 2002.

[136] E. L. Olivares, M. P. Marassi, R. S. Fortunato et al., “Thyroid function disturbance and type 3 iodothyronine deiodinase induction after myocardial infarction in rats-a time course study," Endocrinology, vol. 148, no. 10, pp. 4786-4792, 2007.

[137] C. Fekete, B. Gereben, M. Doleschall et al., "Lipopolysaccharide induces type 2 iodothyronine deiodinase in the mediobasal hypothalamus: implications for the nonthyroidal illness syndrome," Endocrinology, vol. 145, no. 4, pp. 1649-1655, 2004.

[138] E. Sánchez, P. S. Singru, G. Wittmann et al., "Contribution of TNF- $\alpha$ and nuclear factor- $\kappa$ B signaling to type 2 iodothyronine deiodinase activation in the mediobasal hypothalamus after lipopolysaccharide administration," Endocrinology, vol. 151, no. 8, pp. 3827-3835, 2010. 


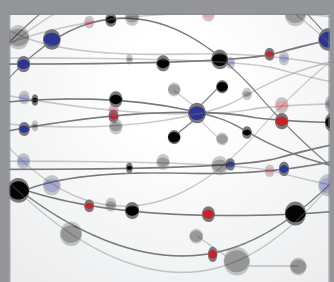

The Scientific World Journal
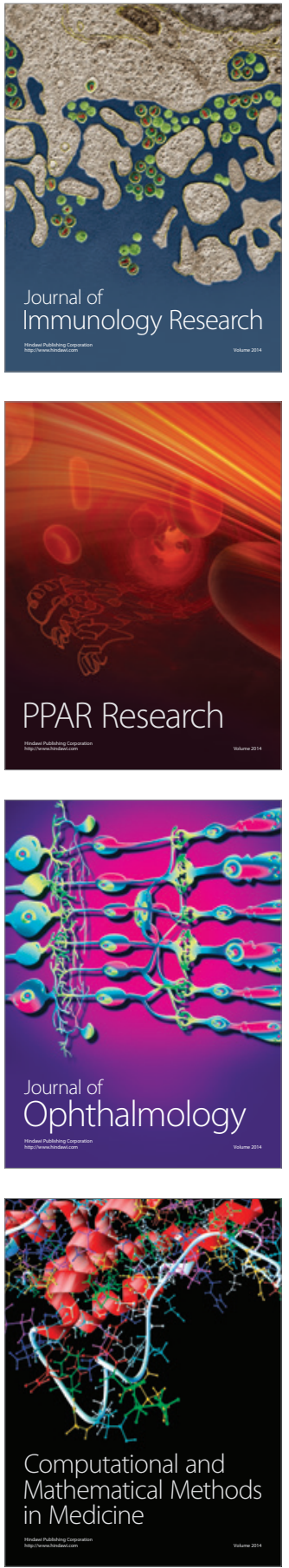

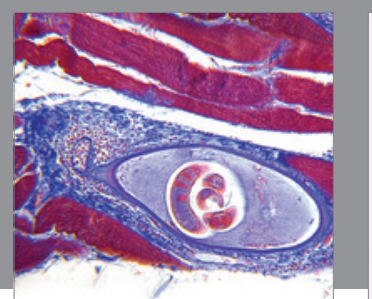

Gastroenterology Research and Practice

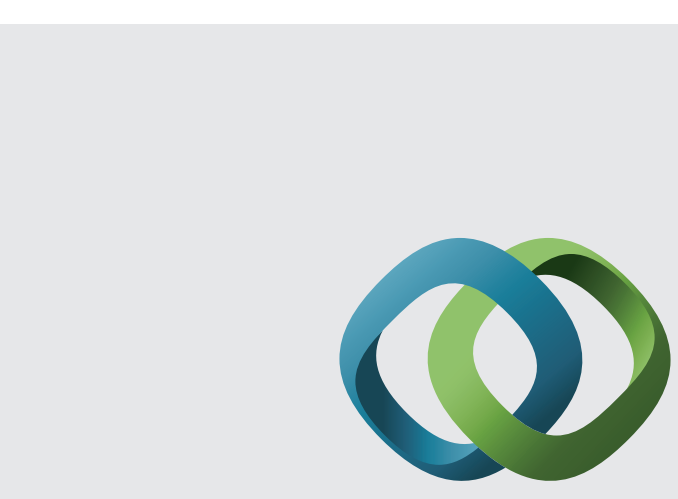

\section{Hindawi}

Submit your manuscripts at

http://www.hindawi.com
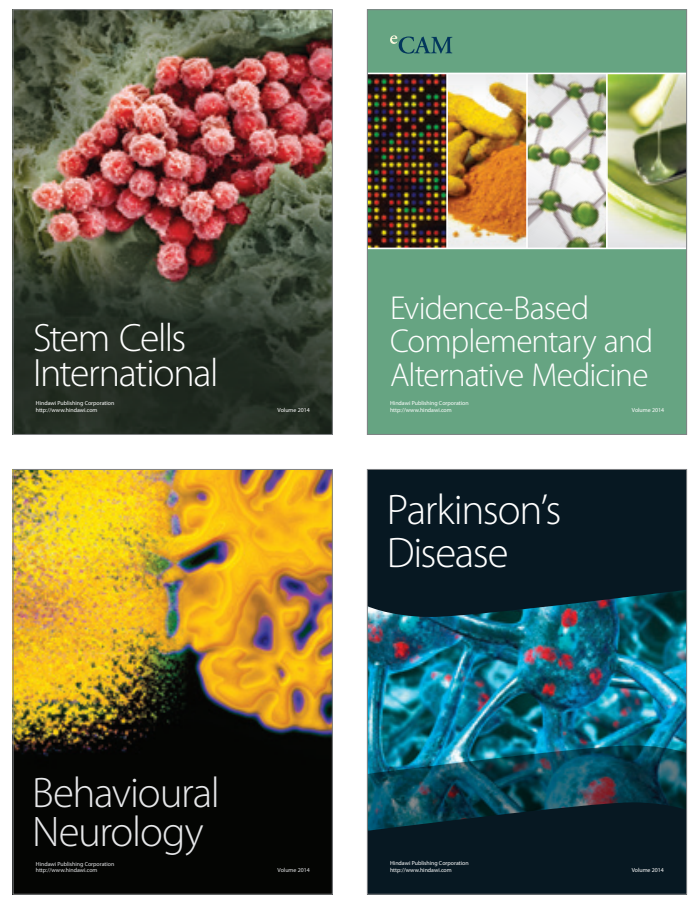
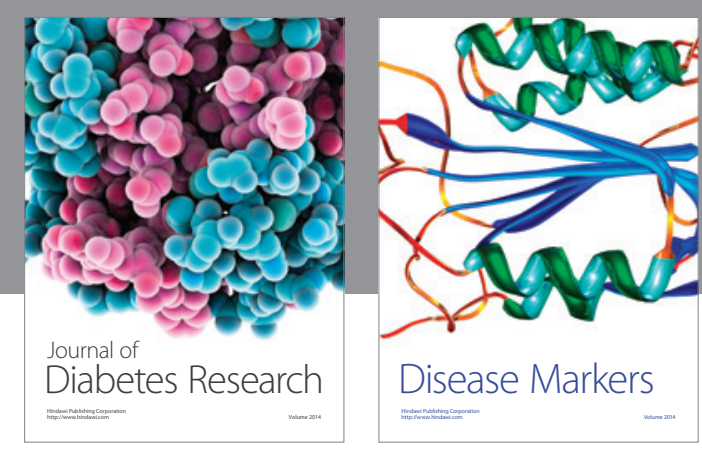

Disease Markers
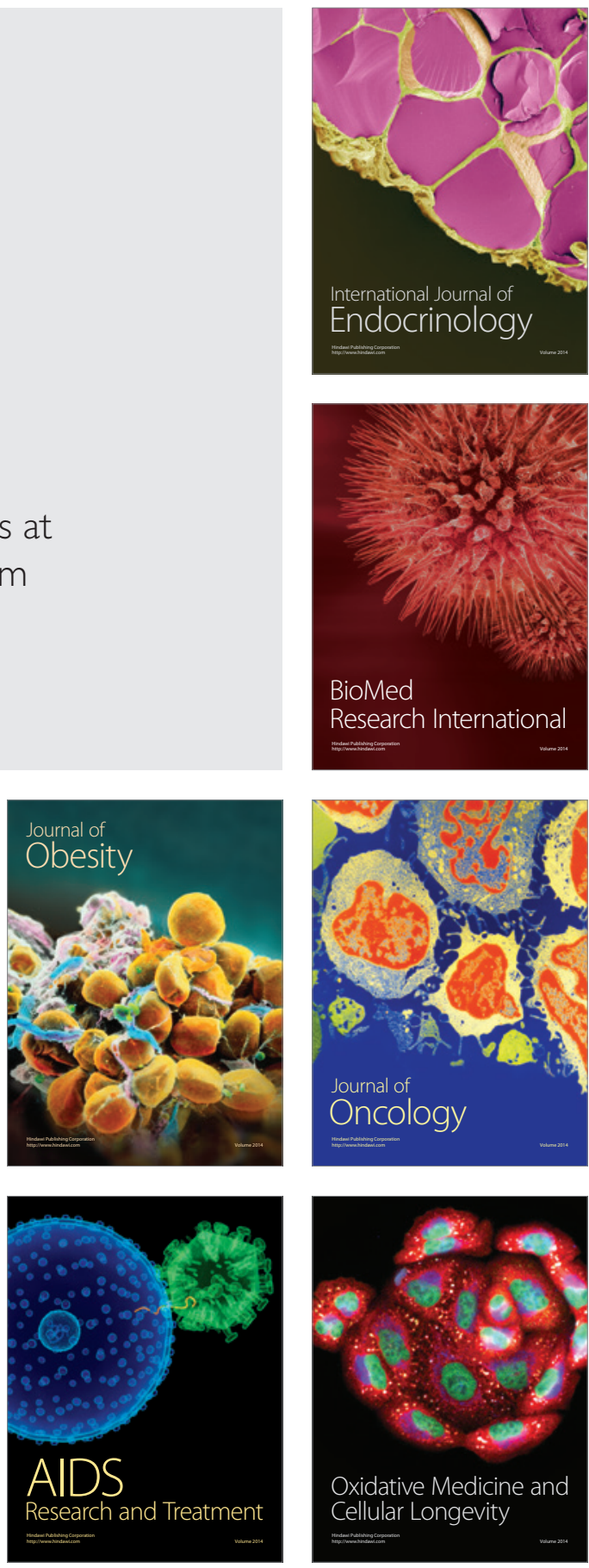